\title{
Open Fractures of the Ankle Joint and the Hindfoot
}

\author{
Camilo A Delgadillo ${ }^{1}$, Eduard J Salavarrieta ${ }^{2}$, Rodrigo F Pesantez ${ }^{3}$
}

\begin{abstract}
Ankle fractures are common lesions in sportive activities and high-velocity trauma, 17\% could be open fractures; obese and older women are more prone. Leading to coverage defects, osteomyelitis, and bone loss. Management of open fracture requires an interdisciplinary team, with extensive knowledge in this complex situation. Treatment in the emergency department includes clear documentation of the wound, including contamination, neurologic and vascular status, radiographic diagnosis and early administration of antibiotics and tetanus prophylaxis, provisional reduction, and splint the extremity. A debridement similar to oncology protocol decreased the probability of infection as a complication. The use of negative pressure wound therapy has a positive impact on wound closure and decreased necrosis of flaps and grafts. Fractures of the hindfoot are least prevalent but may have frequent complications.
\end{abstract}

Keywords: Amputation, Ankle fracture, Debridement, Flap cover, Hindfoot, Open ankle dislocation.

Journal of Foot and Ankle Surgery (Asia Pacific) (2021): 10.5005/jp-journals-10040-1191

\section{INTRODUCTION}

Ankle fractures account for approximately $9 \%$ of all fractures ${ }^{1}$; in open fractures around this joint, the bone is exposed to the environment (Fig. 1), directly or indirectly, through a wound in the skin and underlying soft tissue. ${ }^{2}$ Before the antibiotic era and modern debridement techniques, these injuries were of poor prognosis, resulting in amputation or death, given high infection rates. $^{3,4}$

The incidence of ankle fractures is near to 100 per million/ year, of which $1.5-17 \%$ are open fractures; ${ }^{1,5,6}$ remarkably, open fractures are more likely to occur in obese patients (17\% open and $10 \%$ close). ${ }^{7}$ The mean age of presentation is 55 years, and are more frequent in females. ${ }^{1}$ In elderly patients ( $\geq 65$ years old), open fractures are more common, especially in women $>80$ years. ${ }^{1,8,9}$ The primary trauma mechanism is simple falls, followed by motor vehicle accidents, ${ }^{6}$ while in young men, occur more frequently during sports activities. ${ }^{1,5}$ Fractures of the medial malleolus are associated with a higher incidence of fracture-dislocations of the ankle. ${ }^{6,10}$

The purpose of the treatment of open fractures is to prevent associated complications and achieve superior functional outcomes. Bacterial load at the fracture site is the most critical risk factor for infection. ${ }^{11}$ Nonetheless, multiple blood transfusions, coverage of contaminated wounds, smoking status, peripheral artery disease, and diabetes mellitus are also poor prognosis factors. It has been described that the infection rate following open fractures is more frequent in lower limbs than in upper extremities. ${ }^{4}$ Additionally, patients with increased body mass index are at higher risk of complications following open ankle fractures. ${ }^{7}$

\section{TREATMENT}

The goal of the treatment of open fractures is to achieve bone healing, adequate soft tissue coverage, and a functional limb while avoiding infection. Treatment strategies include surgical debridement of wounds, fracture stabilization, prophylactic antibiotics, and if indicated, early soft tissue coverage. These interventions must be performed considering the patient's condition and the presence of concomitant injuries. ${ }^{12}$

\begin{abstract}
${ }^{1-3}$ Department of Orthopedics and Traumatology, Hospital Universitario Fundacion Santa fe de Bogota, Bogota, Colombia

Corresponding Author: Camilo A Delgadillo, Department of Orthopedics and Traumatology, Hospital Universitario Fundacion Santa fe de Bogota, Bogota, Colombia, Phone: +57(300)3050393, e-mail: cdelgadillog@hotmail.com

How to cite this article: Delgadillo CA, Salavarrieta EJ, Pesantez RF. Open Fractures of the Ankle Joint and the Hindfoot. J Foot Ankle Surg (Asia Pacific) 2021;8(4):172-179.
\end{abstract}

Source of support: Nil

Conflict of interest: None

In managing patients with open fractures, all interventions aim to "preserve life, preserve the extremity, and preserve function", ideally in that order. ${ }^{2}$ The initial assessment of these patients must include evaluating the trauma mechanism, the setting in which the injury occurs, the neurovascular status of the extremity, and soft tissues' condition. ${ }^{2}$ Following macroscopic contamination removal, wounds are covered with sterile dressings, fractures, and dislocations are reduced, and temporary stabilization is provided with a splint. It is recommended to obtain photographic documentation of the wound before it is covered to avoid repetitive exposures to the environment (Fig. 1).

A vascular injury should be suspected in the absence of dorsalis pedis artery pulse, pallor, coldness, or other signs of impaired distal perfusion and must be confirmed by arterial Doppler, eco-Doppler ankle/arm index, or computed tomography (CT) angiography. In the case of abnormal findings, the extremity's alignment is verified, and the requirement of vascular exploration is assessed. ${ }^{2}$ Injury to peripheral nerves is suspected by the absence of plantar sensibility and decreased muscle strength. Despite their nature, experimental studies have demonstrated a significant risk of compartment syndrome after open fractures resulting from high energy trauma; ${ }^{13}$ therefore, it is essential to rule out this condition.

The ankle is particularly susceptible to open fractures due to the limited muscle tissue surrounding the joint and the malleoli's subcutaneous location. The state of the soft tissues around the ankle defines the treatment approach; consequently, the skin, 


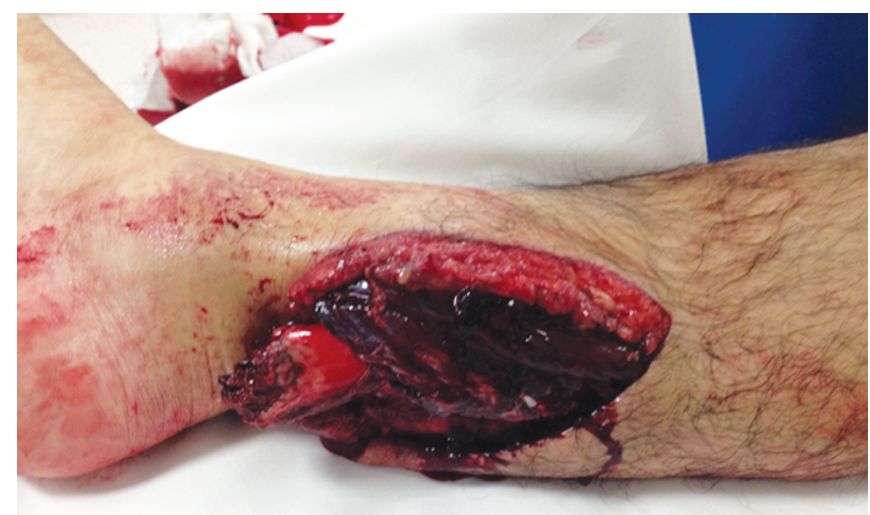

Fig. 1: Open fracture of distal tibia with coverage defect

muscles, tendons, nerves, and vessels are evaluated thoroughly. The Tscherne classification ${ }^{14}$ and the AO/OTA classification ${ }^{15}$ are the most commonly used classification systems for soft tissue injuries; regardless of their limitations, are helpful to establish prognosis and guide treatment. Tscherne III or AO/OTA III injuries are treated with damage control and provisional fracture stabilization instead of definitive fixation.

Remarkably, in the treatment of open fractures of the ankle, the only variables under the surgeon's control are fracture reduction and fixation, soft tissue debridement, and the coverage of defects. ${ }^{5}$

\section{Debridement}

Historically, the management of open fractures was outlined by the "6-hour rule", in which the patient had to undergo surgical irrigation and debridement. ${ }^{16}$ However, this concept has been debated in recent literature. In a study of 554 open fractures in children, the authors did not demonstrate significant differences in infection rates between patients treated within 6 hours and those treated beyond this period. ${ }^{17}$ Similarly, Bednar and Parikh reported an incidence of deep infection of $4.9 \%$ in 82 Gustilo and Anderson (G\&A) type III open fractures where only $24 \%$ of patients underwent surgical debridement in $<6$ hours (mean time from injury to treatment of 8.8 hours). ${ }^{12}$ To date, there is no solid evidence for considering debridement as a surgical emergency; nonetheless, as a general recommendation, it must be performed promptly according to the patient's condition. ${ }^{5}$

Prospective studies have demonstrated that residual necrotic tissue is associated with a higher incidence of infection. ${ }^{18}$ Successful surgical debridement consists of radical removal of all non-viable skin, subcutaneous tissue, muscle, and bone. For the muscle, the 4 C's rule helps determine its viability: color, contractility, consistency, and capability of bleeding; any tissue that does not comply with these characteristics must be excised.

There is broad variability in the literature regarding the adequate debridement extent. However, it has been described that less contaminated injuries benefit from limited debridement, while severely contaminated wounds require a more aggressive approach.

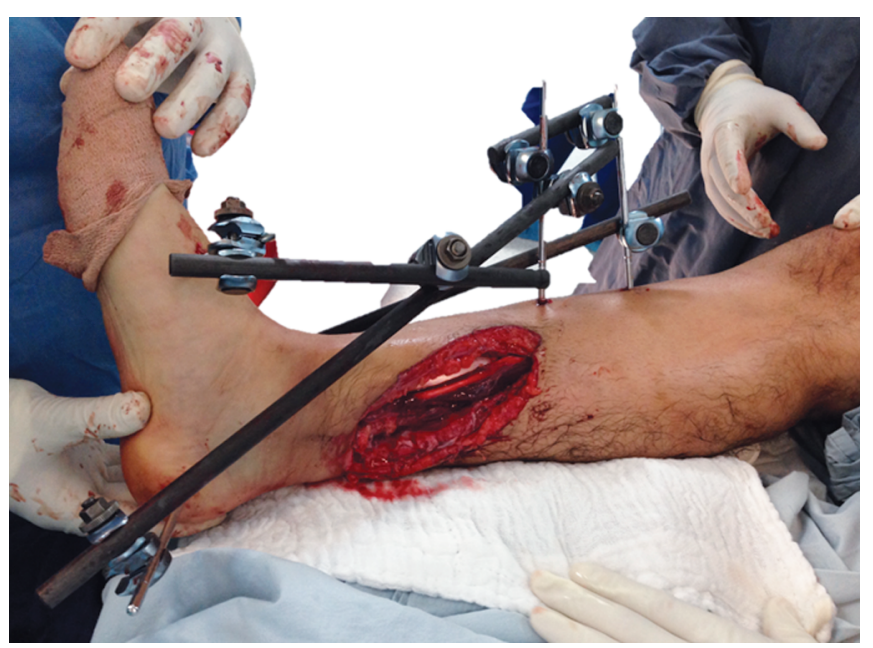

Fig. 2: After an extensive debridement and irrigation, reduction of the fracture and damage control with an external fixator

One of the authors (RP) recommends that debridement must be performed by an experimented fully trained surgeon, implementing an extended excision protocol similar to that used in tumor resection. ${ }^{19} \mathrm{~A}$ separate set of instruments (scalpel, tissue forceps, right-angle retractors, and a curette) are used only for the debridement to avoid cross-contamination. After this step, surgical drapes, gowns, and gloves are changed, and the limb is prepared again for fracture stabilization.

\section{Irrigation}

Surgical irrigation allows removing contamination and necrotic non-viable tissue to decrease bacterial load: "dilution is the solution of the pollution" ${ }^{\prime \prime}$ (Fig. 2). The study by the Fluid Lavage of Open Wounds (FLOW) group published in 2005 compared the use of soapy solutions and saline irrigated at different pressures and demonstrated that low-pressure irrigation with sterile saline is the preferred option, ${ }^{20}$ given that excessive irrigation pressure might cause further injury to the tissues and impaction of external particles into the wound.

\section{Antibiotics}

Experimental studies of bacterial inoculation in bone compared the effectiveness of prophylactic antibiotics given at 2, 6, and 24 hours after the injury and found that administration within 6 hours was protective against infection. ${ }^{21}$ Furthermore, Patzakis and Wilkins ${ }^{11}$ highlighted the benefit of antibiotics administration in $<3$ hours. Therefore, as a general rule, antibiotics must be administered as soon as possible. ${ }^{11,22}$

Antibiotics used in the management of open fractures must cover the main causative microorganism of deep soft tissue infection: gram-positive, gram-negative, anaerobic, and gas-productive bacteria. ${ }^{5}$ The most common microorganism is Staphylococcus aureus, followed by Streptococcus species. In cases of wounds occurring in thoroughly contaminated environments such as farms, swampy waters, fecal waste, and soil, antibiotics against anaerobic germs and Clostridium must be included. ${ }^{11,21,22}$

The antibiotic prophylaxis follows the G\&A classification of open fractures: in grade I, the first-generation cephalosporine for 24 hours is indicated; in grade II, first-generation cephalosporine and aminoglycoside for 48 hours, and in grade III first-generation 
cephalosporine and aminoglycoside for 72 hours. In cases of penicillin allergy, clindamycin can be used. ${ }^{5,12}$

Penicillin is indicated in contaminated wounds with a high risk of necrotizing gangrene by Clostridium. ${ }^{12,23}$ However, penicillin administration in injuries with no risk of infection by these bacteria is questionable ${ }^{18}$ and has been withdrawn from military trauma guidelines.

As mentioned, the timing of antibiotic administration is a prognostic factor for open fracture outcomes. The choice of antibiotics is determined by the wound's characteristics and the setting where it was obtained. The maximum duration of antibiotics is 72 hours in more severe open fractures and only continued for three additional doses after soft tissue coverage procedures. If additional interventions are required, a single dose of prophylactic antibiotic is administered as usual., 24,25 The administration of tetanus immunoglobulin, is a key point in the treatment of wounds, especially those with a high risk of infection and contamination, guide from the Centers for Disease Control and Prevention must be followed (available on https://www.cdc.gov/tetanus/clinicians. html).

\section{Fracture Fixation}

In the past, most open fractures around the ankle were considered contaminated, regardless of the environment in which occurred, and early internal fixation with implants was precluded. In the late nineties, several studies debated this concept. ${ }^{10,26}$ Franklin et al. ${ }^{27}$ published a series of 38 patients who underwent immediate to early fracture fixation without identifying cases of infection. Bray et al. ${ }^{28}$ demonstrated favorable outcomes with early osteosynthesis in patients stable at admission, without associated injuries and clean wounds; they also described that patients with contaminated wounds and multiple injuries benefit from a late fixation; their functional results were limited compared with the first group. The authors also concluded that infection rates were reduced by timely antibiotic administration and optimal surgical debridement.

Moreover, early fracture fixation might be advantageous for the soft tissues as it decreases the tension caused by unstable fractures or deformed bones, improves blood flow and lymph drainage, and facilitates wound care. ${ }^{5,25}$ Friedrich ${ }^{29}$ and Wijendra et al. ${ }^{9}$ found a positive association between stable constructs for fracture fixation and lower rates of infection, and improved functional outcomes ${ }^{30}$ (Fig. 3). Open fractures that occur in less contaminated or clean settings, G\&A grade I and II, must undergo early fixation. ${ }^{5}$

In skin necrosis, macroscopic contamination with soil or swampy waters, blood blisters, and whether primary skin closure is not possible (i.e., soft-tissue edema), temporary fracture stabilization with a splint or external fixator is recommended. Whenever possible, primary wound closure is preferred to decrease skin tension and keep the wound sterile. Conversion to internal fixation is completed within 6.9 days after the first procedure. ${ }^{6}$

\section{Soft Tissue Defect Coverage}

Skin necrosis might be present in approximately $16 \%$ of surgical wounds after ankle fracture fixation. Risk factors related to this outcome are male sex, diabetes, ASA 2, and open fractures G\&A III. ${ }^{25}$ In ankle fractures complicated with skin necrosis, surgical debridement of non-viable tissue, cultures to rule out deep surgical site infection, and the use of negative pressure systems (NPS) must be accomplished. Serial debridement and NPS exchanges help

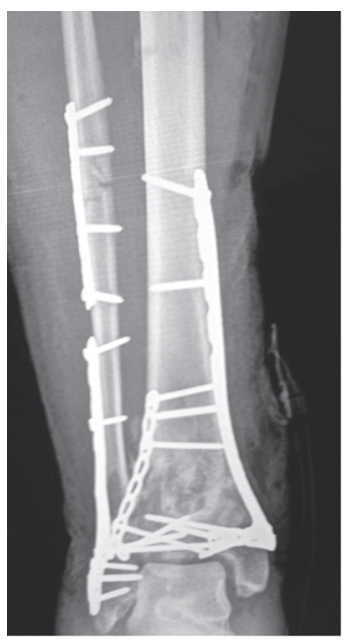

Fig. 3: Stable fixation of fractures helps to decrease the risk of infection

delimit the necrosis extension and assess the appropriate coverage options according to the residual defect.

The preferred moment to cover soft-tissue defects in the lower limbs has been reviewed extensively. Historically, closure by the secondary intention was the standard of care to decrease gas gangrene risk. However, publications from the end of the twentieth century, in which timing of defect coverage was grouped in $<3$, $3-90$, and $>90$ days, demonstrated that defects managed in $<3$ days after the injury had lower reoperation rates, fewer infections, and a lower length of stay. ${ }^{31}$ These findings were confirmed by Liu et al. $^{32}$ in a study of 105 patients, where patients receiving free flaps within three days from injury presented better outcomes than those treated in 7 days.

The one-stage management protocol of covering defects and performing fracture fixation developed by Gopal, ${ }^{33}$ known as "fix and flap", consist of covering defects associated with open fractures of the tibia G\&A IIIB and IIIC within 24-72 hours. This treatment approach reached better results compared with delayed coverage procedures. Regardless of the method, it has been described that rotational and local flaps present higher rates of failure, skin necrosis, and reoperations, mainly when the conditions of the bed and surrounding tissues are lacking. ${ }^{34}$

With the significant increase of cases of open fractures with soft tissue defects, the British Association of Plastic, Reconstructive and Esthetic Surgeons (BAPRAS) and the British Orthopaedic Association (BOA) published in 2009 "the standards of care of open fractures". ${ }^{35}$ Recommendation for defect coverage should be performed with in 72 hours to decrease the risk of infection and to complete open reduction and internal fixation in the same stage. Finally, emphasize providing adequate soft tissue coverage to enhance bone healing.

Likewise, recent studies demonstrated that early fixation and defect coverage in elderly patients reduce prostration, allow early rehabilitation, positively impact functional outcomes, and decrease fatal outcomes. Mortality after open fractures of the ankle is similar to that after hip fractures..$^{8,9}$

Soft tissue coverage must be performed preferably within 72 hours after injury, along with fracture fixation, in the same procedure. Free flaps are recommended over local flaps, given the increased risk of complications in the latter, mainly due to the injury's severity. 


\section{Negative Pressure Wound Therapy}

If the patient is unstable, immediate coverage by a microsurgeon is not available, and the soft tissues are not adequate for a flap or primary closure, the use of negative pressure wound therapy (NPWT) is indicated. Moreover, it has been demonstrated to decrease the risk of deep infection by $80 \% .^{36}$

The NPWT decreases the wound exudate and the number of metalloproteinases produced by the inflammatory reaction, increases capillary perfusion, and stimulates granulation tissue production to promote a more favorable bed for coverage. However, by itself, NPWT cannot generate epithelial tissue. The prolonged use of NPWT might cause additional damage to soft tissues and joint contractures; therefore, coverage should not be delayed, aiming NPWT therapy. ${ }^{37,38}$

In the prospective study by Stannard et al., ${ }^{39}$ the use of NPWT demonstrated significant improvements in the quality of life of patients and a reduced rate of deep infection compared with the control group (5.4\% NPWT vs $20 \%$ no NPWT). Similarly, Joethy et al., ${ }^{40}$ in a retrospective study of 69 patients with open fractures requiring flaps (51 NPWT and 18 control), found that the deep infection rate in the NPWT group was $10 \%$ vs $33 \%$ in the control group, and flap failure rates of $6 \%$ with NPWT vs $11 \%$ without NPWT. Conversely, more recently, the randomized control trial published by Costa et al. ${ }^{41}$ showed no difference in the disability index at 12 months after injury, the prevalence of deep infection, nor wound complications while comparing the use of NPWT against standard dressings.

The NPWT help managing lower limb trauma (Fig.4). It improves wound healing, neovascularization, decreases the size of soft tissue defects by promoting granulation, and decreases bacterial contamination. Furthermore, decreased secondary necrosis risk by reducing exudate and hematomas in flaps postoperative care.

\section{Amputation}

A mangled or severely injured extremity is defined as the damage of three or more of the systems that constitute it (tegument, nerves, vessels, or bone). This scenario's primary approach is to decide whether the limb is appropriate for salvage or amputation is indicated. Advances in wound care such as NPWT and modern techniques of free flaps have increased the rate of successful limb salvage of extremities that were deemed to amputation.

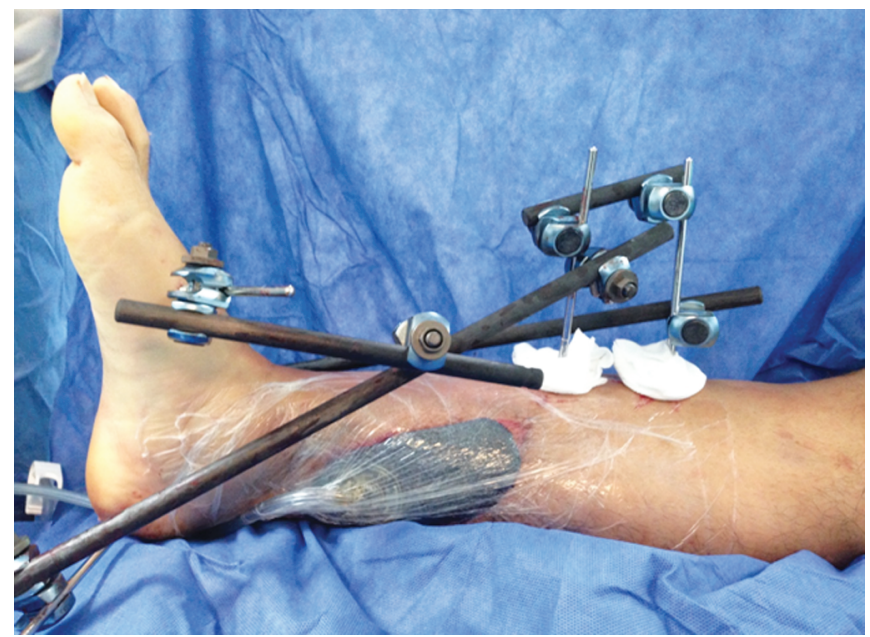

Fig. 4: NPWT in damage control and flap coverages is a useful tool
The criteria to assess severely injured extremities are provided by the Mangled Extremity Severity Score (MESS), the Limb Salvage Index (LSI), and the Predictive Salvage Index (PSI). ${ }^{42}$ The most used scale is the MESS, which provides a positive predictive value of $100 \%$ for amputation in patients with scores $>7 i^{43}$ the main limitation of this scale is that most of the studies used for its development were retrospective, leading to classification bias and inaccuracy in decision making. The Lower Extremity Assessment Project (LEAP) study in 2010 demonstrated that the MESS has low sensitivity but reasonable specificity in the initial assessment of the injury ${ }^{2,34}$ and low sensitivity and specificity for tibial nerve injury and drop foot, as criteria for amputation. This study also described some extent the recovery of plantar sensation in severe injuries. ${ }^{34}$

Other factors, such as socioeconomic status and comorbidities before the injury, are related to the prognosis of patients with mangled extremities; these variables have also negatively impacted patients' functional outcomes and quality of life. ${ }^{34}$ Furthermore, limb salvage is associated with higher rates of complications such as reoperations, readmissions, and chronic pain, without significant differences between salvage and amputation in return rates to work after two years from injury. ${ }^{34}$ However, amputations might be more costly in the long-term.

Primary amputation in lower-limb trauma is reserved for cases of partial traumatic amputation, cold ischemia, non-reparable vascular injuries, or uncontrollable bleeding in patients with hemodynamic shock. Treatment delay of $>6$ hours has been associated with hemodynamic instability, rhabdomyolysis, and the requirement of late amputation. In addition, in the setting of degloving injuries and loss of muscle tissue that affects more than two compartments of the leg, the BAPRAS guidelines are recommended to deliberate the decision between two surgeons, with previous detailed analysis of the case and ideally with patients and family consent. ${ }^{35}$

\section{Management of Infection}

After open fractures, deep infection incidence is around $8 \%,{ }^{44}$ where obese and smoking patients are at higher risk. ${ }^{7}$ This complication is managed with surgical irrigation and debridement, culture samples, and targeted antibiotics.

Fang et al. ${ }^{45}$ described a treatment strategy according to the onset of infection. If the infection occurs after complete fracture healing, implant removal is performed, followed by irrigation and debridement, and antibiotics; irrigation might be repeated according to the patient's response. In acute infection or infection without fracture healing, implant retention is preferred, along with irrigation, debridement, and antibiotics. In the absence of improvement, the implant should be removed or exchanged. However, if implant removal is not possible or the patient is not fit for surgery, suppressive antibiotic therapy is indicated. ${ }^{45}$

During the surgical procedure, third spaces must be avoided as this allows the bacterial colonization of hematomas or fluid collections. The treatment of deep infection with local antibiotic and antibiotic-loaded cement pearls has demonstrated promising results in infection control and decreasing the likelihood of toxicity of systemic antibiotics. ${ }^{46}$

Several prospective and retrospective studies in open fractures have shown the benefits of timely wound closure and local antibiotics. ${ }^{47,48}$ In refractory infections and osteomyelitis after open fractures, the use of intramedullary cemented rods for ankle arthrodesis has demonstrated favorable results. ${ }^{46,49}$ Alternatively, 


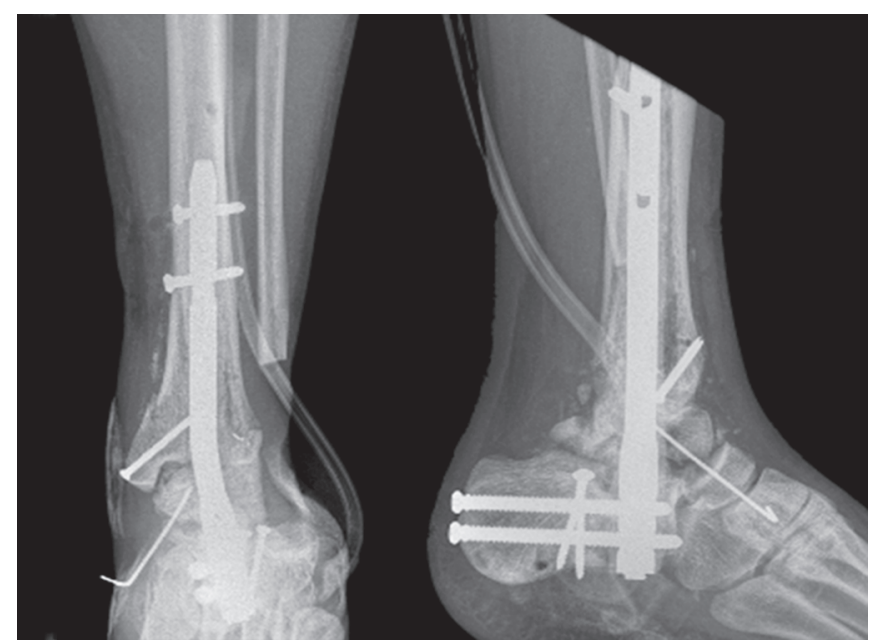

Fig. 5: Patient with persistent infection after a distal tibial and calcaneus open fracture, final treatment with ankle arthrodesis with intramedullary nail with antibiotic

antibiotic-loaded cement spacers (Fig. 5), ceramics, and bioactive glass have been widely used for infection control with acceptable results. ${ }^{46}$

Deep infection after open fractures decreases the chance of positive outcomes, leading to multiple interventions, impaired fracture consolidation, and late amputations. ${ }^{5,6}$ Complications such as wound dehiscence, superficial infections, and non-union are twice as common in the open (33\%) than close fractures (11\%). ${ }^{6}$

\section{Special Considerations}

\section{War Injuries}

Unfortunately, war has provided a significant number of lessons about open fractures and severely injured extremities. Registries demonstrate that around 500,000 gunshot wounds are observed in both developed and developing countries each year. In our country, war and violence are the leading cause of death of men between 15 years and 44 years old. ${ }^{50}$ During the war in Iraq and Afghanistan, over 1,300 lower-limb amputations were performed in the United States. ${ }^{51}$ Explosions cause severe damage to soft tissue due to thermal and mechanical trauma and are considered highly contaminated wounds. Explosives (mainly hand-made) are usually contaminated with fecal material and soil, increasing the risk of polymicrobial infections (anaerobic or gram-negative bacteria) and reducing the chance of salvage. ${ }^{50}$

Low-velocity gunshot wounds produce less severe trauma to the soft tissues and can be treated without antibiotics; however, high-velocity or fragmentation projectiles are considered G\&A type III open fractures and treated accordingly. ${ }^{50}$

Most military trauma victims have multiple concomitant injuries, and efforts should be addressed to resuscitate and manage life-threatening injuries such as thoracic, abdominal, vascular, or traumatic amputations. Suarez et al. ${ }^{50}$ in the Central Military Hospital of Bogotá, Colombia, a referral center of military trauma, described a protocol of treatment, starting with the assessment of the wound, coverage with sterile sponges, administration of antibiotics, irrigation, debridement, cultures, and external fixation for fracture stabilization. After 48 hours, surgical irrigation, debridement, and cultures are repeated. Interestingly, the authors describe that the main microorganisms found in these wounds were: S. aureus (36\%), of which 50\% were sensitive to oxacillin, $10 \%$ to aminoglycoside, $10 \%$ to clindamycin, and $100 \%$ resistance to first-generation cephalosporins. According to these findings, highvelocity gunshot wounds are treated with oxacillin, aminoglycoside, and penicillin. On the other hand, microorganisms isolated in wounds from antipersonnel mines were Enterobacter faecalis (15\%), Escherichia coli, and Pseudomonas aeruginosa (13\%); ${ }^{50,52}$ therefore, broad-spectrum antibiotics such as clindamycin, aminoglycoside, or metronidazole are recommended. ${ }^{18,50,52}$

During the Korean War, a high incidence of Clostridium infections was identified; ${ }^{18}$ however, recent series of Iraq and Afghanistan show bacterial isolations similar to those described in the Colombian series, with different resistance patterns; $15 \%$ of their cases resulted in osteomyelitis. ${ }^{53}$

Prophylaxis against the hepatitis B virus was recommended in non-vaccinated patients after the isolation of virus fragments in Israeli war bombs. ${ }^{18}$

Limb reconstruction after war injuries must be delayed until negative cultures are obtained, and the patient is in optimal condition, both nutritionally and physiologically, ideally after the fifth day. ${ }^{18}$ Different authors have highlighted the benefits of NPWT in decreasing the number of surgical debridement in these patients. $^{18,38}$

It must be considered that bone grafts and osteosynthesis hardware might perpetuate a non-treated infection; therefore, management with circular or hybrid external fixations helps treat these injuries. ${ }^{54}$ Innervated flaps aimed to restore the foot sole's sensibility have not demonstrated a significant difference in ulcer onset than non-innervated flaps. ${ }^{38}$ In soft tissue coverage, skin grafts might retract and hinder joint mobility; therefore, fasciocutaneous flaps are preferred. ${ }^{38}$

\section{Pilon Fractures of the Ankle}

These fractures, produced by high-energy axial trauma, are challenging due to the severity of associated soft tissue injury, fracture comminution, and damage to the articular surface. ${ }^{55}$ Given that anatomical reconstruction of the joint surface is nearly impossible with minimally invasive techniques, more extensive surgical approaches are required; Sirkin et al. ${ }^{56}$ presented a staged protocol for managing these fractures. The fracture should be stabilized with a splint in the emergency room. In the first surgical stage, debridement, lateral column internal fixation, and the medial column's external fixation to maintain the length are performed. In the meantime, a CT scan is obtained for preoperative planning of fracture reduction and fixation. Finally, when the soft tissues are adequate, a second stage is performed, in which the external fixator is removed, and the pilon fracture is fixed, aiming to restore the anatomy of the ankle. A mean of 14 days between stages is suggested. The authors reported a rate of $9 \%$ of complications: two patients developed osteomyelitis, and one was amputated.

Liu et al. ${ }^{57}$ published a series of 18 cases of open pilon fractures G\&A IIIB treated with a staged protocol; in the second stage, soft tissue defect coverage was carried out. Reported two cases of partial necrosis of the flap and fracture consolidation in 5-6 months, without implant failure. The authors concluded that open pilon fractures must be treated with a staged approach. Similarly, Zeng et al. ${ }^{58}$ described 28 cases of open pilon fractures. Recommendation for low-energy G\&A I be treated with a single staged open reduction and internal fixation, while G\&A II and III require external fixation and staged treatment. 


\section{Talus Fractures}

Around $20-25 \%$ of talus fractures are open, ${ }^{59}$ and $18-25 \%$ are located in the neck. Are usually secondary to high-energy trauma such as falls from height and motor vehicle accidents. Talus fractures often present with associated calcaneus and malleoli fractures. Forty percent of injuries around the ankle and hindfoot are talus dislocations. Deep infection is the most common complication (25\%), followed by avascular necrosis. ${ }^{60}$

Recommendations for this open fracture treatment are to perform the debridement and fracture reduction through the same approach if possible and always attempt primary skin closure. In more severe cases, fracture reduction and stabilization with an external fixator and NPWT are used, allowing complete edema resolution before definitive fixation. Liu et al. ${ }^{59}$ described a $41 \%$ infection rate after the treatment of open talus fractures, with $81 \%$ deep infections and $85 \%$ of cases occurring during the first 2 weeks. The authors also find that severely compromised joint surfaces and G\&A II and III were more associated with complications.

\section{Calcaneus Fractures}

Intra-articular and displaced fractures of the calcaneus are complex injuries that significantly affect patients' quality of life and functional outcomes. Open fractures of the calcaneus are rare but are usually caused by high-energy trauma. ${ }^{61}$

Spierings et al. ${ }^{61}$ performed a systematic review of 18 articles, including 589 patients, $50.1 \%$ G\&A grade III. In fractures G\&A I, there was $11.8 \%$ of infection and $66 \%$ in grade III, of which $55 \%$ were managed with external fixation, and $10 \%$ of amputations occurred in patients undergoing closed management. The author concluded that these findings might be explained by the higher amount of severe and complex fractures and that early infections precluded definitive fixation. Patients with a lower rate of complications underwent open reduction and internal fixation through an extended lateral approach, probably those with less severe injuries.

Thoroughly irrigation and debridement and early fracture reduction and stabilization might reduce the risk of infection and associated complications. ${ }^{62}$ Wounds in the medial side of the hindfoot associated with a medial fracture fragment of the sustentaculum must be reduced promptly to avoid further skin lesions. In severe injuries, the external fixator must span from the tibia to the medial cuneiform or the first metatarsal base, and NPWT is indicated. ${ }^{61}$

\section{Conclusion}

Open fractures around the ankle are prevalent. It is crucial to recognize the severity of the injury to provide adequate treatment. Timely administration of prophylactic antibiotics, protecting the wound with sterile sponges and dressings, prioritizing surgical irrigation and debridement, and performing a thorough removal of non-vital tissues are essential for success.

In G\&A III, the antibiotic treatment, must last 72 hours. Early fracture fixation and reduction and soft tissue coverage must be attempted whenever possible. On the contrary, with highly contaminated wounds, military injuries, and unstable polytrauma patients, fracture stabilization with external fixation is the first choice.

The application of NPWT has been demonstrated to decrease the rate of amputations in mangled extremities and decrease the complexity of soft tissue defects, increasing the rate of successful salvages. In severe trauma with the joint surface's involvement, recurrent infections, and osteomyelitis at the distal tibia or talus, ankle arthrodesis with intramedullary rods covered with antibioticloaded bone cement has been helpful in infection control at our institution.

\section{Recommendations}

- At the emergency room:

- Administer antibiotic prophylaxis and tetanus prophylaxis as soon as possible.

- Remove macroscopic contamination.

- Obtain photographic documentation of the wound and related injuries.

- Obtain pertinent diagnostic images.

- Reduce fractures and dislocations and splint.

- Obtain additional diagnostic test.

- Take the patient to the operating room as soon as possible to:

- Perform surgical irrigation and debridement, with broad margins of resection.

- Fracture reduction and fixation according to the pattern and location of the fracture.

- In cases of highly contaminated wounds: temporary external fixation.

- Primary wound closure avoiding tension, use of NPWT, immediate or delayed flaps (according to the clinical conditions of the patients and availability of trained microsurgeon).

\section{References}

1. Bugler KE, Clement ND, Duckworth AD, et al. Open ankle fractures: who gets them and why? Arch Orthop Trauma Surg 2015;135(3):297303. DOI: $10.1007 / \mathrm{s} 00402-014-2140-3$.

2. Manway J, Highlander P. Open fractures of the foot and ankle: an evidence-based review. Foot Ankle Spec 2015;8(1):59-64. DOI: 10.1177/1938640014557072.

3. Pape HC, Webb LX. History of open wound and fracture treatment. J Orthop Trauma 2008;22(10 Suppl):133-134. DOI: 10.1097/ BOT.0b013e318188e26b.

4. Bowen TR, Widmaier JC. Host classification predicts infection after open fracture. Clin Orthop Relat Res 2005;433(433):205-211. DOI: 10.1097/01.blo.0000150345.51508.74.

5. Dhillon MS, Rajnish RK, Saini UC, et al. Open fractures of the ankle: management options and factors influencing outcomes. J Foot Ankle Surg (Asia Pacific) 2017;4(2):69-76. DOI: 10.5005/ jp-journals-10040-1074.

6. Simske NM, Audet MA, Kim C-Y, et al. Open ankle fractures are associated with complications and reoperations. OTA Int Open Access J Orthop Trauma 2019;2(4):e042. DOI: 10.1097/ Ol9.0000000000000042.

7. Gil JA, Durand W, Johnson JP, et al. Effect of obesity on perioperative complications, hospital costs, and length of stay in patients with open ankle fractures. J Am Acad Orthop Surg 2019;27(11):e529-e534. DOI: 10.5435/JAAOS-D-17-00860.

8. Toole WP, Elliott M, Hankins $D$, et al. Are low-energy open ankle fractures in the elderly the new geriatric hip fracture? J Foot Ankle Surg 2015;54(2):203-206. DOI: 10.1053/j.jfas.2014.10.015.

9. Wijendra A, Alwe R, Lamyman M, et al. Low energy open ankle fractures in the elderly: outcome and treatment algorithm. Injury 2017;48(3):763-769. DOI: 10.1016/j.injury.2016.11.014.

10. Johnson EE, Davlin LB. Open ankle fractures: the indications for immediate open reduction and internal fixation. Clin Orthop Relat Res 1993;292(292):118-127. DOI: 10.1097/00003086-199307000-00014. 
11. Patzakis MJ, Wilkins J. Factors influencing infection rate in open fracture wounds. Clin Orthop Relat Res 1989;243(243):36-40. DOI: 10.1097/00003086-198906000-00006.

12. Bednar D, Parikh J. Effect of time delay from injury to primary management on the incidence of deep infection after open fractures of the lower extremities caused by blunt trauma in adults. J Orthop Trauma 1993;7(6):532-535. DOI: 10.1097/00005131-199312000-00008.

13. Altay MA, Ertürk C, Altay N, et al. Comparison of intracompartmental pressures in a rabbit model of open and closed tibial fractures: an experimental study. J Bone Jt Surg - Ser B 2013;95B(1):111-114. DOI: 10.1302/0301-620X.95B1.29504.

14. Ibrahim DA, Swenson A, Sassoon A, et al. Classifications in brief: the Tscherne classification of soft tissue injury. Clin Orthop Relat Res 2017;475(2):560-564. DOI: 10.1007/s11999-016-4980-3.

15. Ruedi T, Murphy WM. AO principles of fracture management 2000. p. 868.

16. Friedrich P. Die aseptische versorgung frischer Wunden unter von Infectionsrregem in frischen Wunden. Arch klin Chir 1989;57:288-310.

17. Skaggs $D$, Friend $L$, Alman B. The effect of surgical delay on acute infection following 554 open fractures in children. J Bone Jt Surg Am 2005;87(8):8-12. DOI: 10.2106/JBJS.C.01561.

18. Lindberg R, Wetzler T, Marshall J, et al. The bacterial flora of battle wounds at the time of primary debridement: a study of the Korean battle casualty. Ann Surg 1955;141(3):369-374. DOI: 10.1097/00000658-195503000-00012.

19. Chummun S, Wright T, Chapman T, et al. Outcome of the management of open ankle fractures in an ortho-plastic specialist centre. Injury 2015;46(6):1112-1115. DOI: 10.1016/j.injury.2014.12.017.

20. Bhandari $\mathrm{M}$, Jeray $\mathrm{K}$, Petrisor $\mathrm{B}$, et al. A trial of wound irrigation in the initial management of open fracture wounds. N Engl J Med 2015;373(27):2629-2641. DOI: 10.1056/NEJMoa1508502.

21. Penn-Barwell J, Murray C, Wenke J. Early antibiotics and debridement independently reduce infection in an open fracture model. 2012;94(1):107-112. DOI: 10.1302/0301-620X.94B1.27026.

22. Schenker M, Yannascoli S, Baldwin K, et al. Does timing to operative debridement 23 affect infectious complications in open long-bone fractures? A systematic review. J Bone Jt Surg Am 2012;94(12):10571064. DOI: $10.2106 / J B J S . K .00582$.

23. Patzakis M, Harvey J, Ivler $D$. The role of antibiotics in the management of open fractures. J Bone Jt Surg Am 1974;56(3):532-541. DOI: 10.2106/00004623-197456030-00010.

24. Dellinger E, Caplan E, Weaver L. Duration of preventive antibiotic administration for open extremity fractures. Arch Surg 1988;123(3):333-339. DOI: 10.1001/archsurg.1988.01400270067010.

25. Ovaska M, Madanat R, Mäkinen T. Predictors of postoperative wound necrosis following primary wound closure of open ankle fractures. Foot Ankle Int 2016;37(4):401-406. DOI: 10.1177/1071100715609182.

26. Chapman $M$, Mahoney $M$. The role of early internal fixation in the management of open fractures. Clin Orthop 1979(138):120-138.

27. Franklin J, Johnson K, Hansen SJ. Immediate internal fixation of open ankle fractures. report of thirty-eight cases treated with a standard protocol. J Bone Jt Surg Am 1984;66(9):1349-1356. DOI: 10.2106/00004623-198466090-00004.

28. Bray TJ, Endicott M, Capra SE. Treatment of open ankle fractures. Clin Orthop Relat Res 1989(240):47-52. DOI: 10.1097/00003086198903000-00007.

29. Friedrich B, Klaue P. Mechanical stability and post-traumatic osteitis: an experimental evaluation of the relation between infection of bone and internal fixation. Injury 1977;9(1):23. DOI: 10.1016/00201383(77)90045-6.

30. Consigliere $\mathrm{P}$, lliopoulos $\mathrm{E}, \mathrm{Ads} \mathrm{T}$, et al. Early versus delayed weight bearing after surgical fixation of distal femur fractures: a nonrandomized comparative study. Eur J Orthop Surg Traumatol 2019;29(8):1789-1794. DOI: 10.1007/s00590-019-02486-4.

31. Godina M. Early microsurgical reconstruction of complex trauma of the extremities. Plast Reconstr Surg 1986;78(3):285-292. DOI: 10.1097/00006534-198609000-00001.
32. Liu D, Sofiadellis F, Ashton M, et al. Early soft tissue coverage and negative pressure wound therapy optimises patient outcomes in lower limb trauma. Injury 2012;43(6):772-778. DOI: 10.1016/j. injury.2011.09.003.

33. Gopal S, Majumder S, Batchelor A, et al. Fix and flap: the radical orthopaedic and plastic treatment of severe open fractures of the tibia. J Bone Jt Surg Br 2000;82(7):959-966. DOI: 10.1302/0301$620 x .82 b 7.10482$.

34. Higgins TF, Klatt JB, Beals TC. Lower extremity assessment project (LEAP) - the best available evidence on limb-threatening lower extremity trauma. Orthop Clin North Am 2010;41(2):233-239. DOI: 10.1016/j.ocl.2009.12.006.

35. Eccles S, Handley B, Khan U, et al., Standards for the management of open fractures of the lower limb. A report by the BAPRAS/BOA working party on the management of open tibial fractures. 2009.

36. Blum M, Esser M, Richardson M, et al. Negative pressure wound therapy reduces deep infection rate in open tibial fractures. $J$ Orthop Trauma 2012;26(9):499-505. DOI: 10.1097/BOT.0b013e31824133e3.

37. Kunze KN, Hamid KS, Lee S, et al. Negative-pressure wound therapy in foot and ankle surgery. Foot Ankle Int 2020;41(3):364-372. DOI: 10.1177/1071100719892962.

38. Baechler MF, Groth AT, Nesti LJ, et al. Soft tissue management of war wounds to the foot and ankle. Foot Ankle Clin 2010;15(1):113-138. DOI: 10.1016/j.fcl.2009.10.006.

39. Stannard J, Volgas D, Stewart R, et al. Negative pressure wound therapy after severe open fractures: a prospective randomized study. J Orthop Trauma 2009;23(8):552-557. DOI: 10.1097/BOT.0b013e3181a2e2b6.

40. Joethy J, Sebastin S, Chong A, et al. Effect of negative-pressure wound therapy on open fractures of the lower limb. Singapore Med J 2013;54(11):620-623. DOI: 10.11622/smedj.2013221.

41. Costa ML, Achten J, Bruce J, et al. Effect of negative pressure wound therapy vs standard wound management on 12-month disability among adults with severe open fracture of the lower limb the WOLLF randomized clinical trial. J Am Med Assoc 2018;319(22):2280-2288. DOI: 10.1001/jama.2018.6452.

42. Durrant C, Mackey S. Orthoplastic classification systems the good, the bad, and the ungainly. Ann Plast Surg 2011;66(1):9-12. DOI: 10.1097/ SAP.0b013e3181f88ecf.

43. Johansen K, Daines M, Howey T. Objective criteria accurately predict amputation following lower extremity trauma. J Trauma 1990;30(5):568-573. DOI: 10.1097/00005373-199005000-00007.

44. Hulsker C, Kleinveld S, Zonnenberg C, et al. Evidence-based treatment of open ankle fractures. Arch Orthop Trauma Surg 2011;131(11):15451553. DOI: 10.1007/s00402-011-1349-7.

45. Fang C, Wong TM, To KKW, et al. Infection after fracture osteosynthesis - part II: treatment. J Orthop Surg 2017;25(1):1-11. DOI: $10.1177 / 2309499017692714$.

46. Metsemakers WJ, Fragomen AT, Moriarty TF, et al. Evidence-based recommendations for local antimicrobial strategies and dead space management in fracture-related infection. J Orthop Trauma 2020;34(1):18-29. DOI: 10.1097/BOT.0000000000001615.

47. Moehring $\mathrm{H}$, Gravel C, Chapman M, et al. Comparison of antibiotic beads and intravenous antibiotics in open fractures. Clin Orthop Relat Res 2000(372):254-261. DOI: 10.1097/00003086-200003000-00028.

48. Ostermann P, Henry S, Seligson D. The role of local antibiotic therapy in the management of compound fractures. Clin Orthop Relat Res 1993(295):102-111. DOI: 10.1097/00003086-199310000-00015.

49. Herrera-Pérez M, Díaz-Fernández $R$, Rendón-Díaz $D$, et al. Tibiotalocalcaneal fusion with antibiotic cement-coated nails for refractory deep infection after ankle ORIF. Foot Ankle Int 2020;41(11):1391-1397. DOI: 10.1177/1071100720939884.

50. Suarez F, Satizabal C, Calderon O, et al. Flora bacteriana en heridas de guerra. Experiencia de dos años en el hospital militar central de Bogotá. Rev Fac Med 2008;16(1):127-133.

51. Tintle SM, Shawen SB, Forsberg JA, et al. Reoperation after combatrelated major lower extremity amputations. J Orthop Trauma 2014;28(4):232-237. DOI: 10.1097/BOT.0b013e3182a53130. 
52. Cabrera M, Ramirez A, Trouchon S, et al. Flora bacteriana en fracturas abiertas de grado III ocasionadas por traumatismo de guerra. Rev Col OrtopTraumatol 2018;32(1):38-42. DOI: 10.1016/j.rccot.2017.07.006.

53. Murray CK, Obremskey WT, Hsu JR, et al. Prevention of infections associated with combat-related extremity injuries. J Trauma Inj Infect Crit Care 2011;71(2 Suppl. 2):S235-S257. DOI: 10.1097/ TA.0b013e318227ac5f.

54. Blair JA, Eisenstein ED, Pierrie SN, et al. Lower extremity limb salvage: lessons learned from 14 years at war. J Orthop Trauma 2016;30(10):S11-S15. DOI: 10.1097/BOT.0000000000000669.

55. He X, Hu Y, Ye P, et al. The operative treatment of complex pilon fractures: a strategy of soft tissue control. Indian J Orthop 2013;47(5):487-492. DOI: 10.4103/0019-5413.118205.

56. Sirkin M, Sanders R, DiPasquale T, et al. A staged protocol for soft tissue management in the treatment of complex pilon fractures. $J$ Orthop Trauma 2004;18(8):32-38. DOI: 10.1097/00005131-20040900100005 .
57. Liu Z, Xu H, Zhang Z, et al. Effectiveness observation of staged treatment of open pilon fracture combined with soft tissue defect. Zhongguo Xiu Fu Chong Jian Wai Ke Za Zhi 2013;27(10):1185-1189.

58. Zeng $X$, Pang G, Ma B, et al. Surgical treatment of open pilon fractures. Orthop Surg 2011;3(1):45-51. DOI: 10.1111/j.1757-7861.2010.00113.x.

59. Liu $X$, Zhang H, Liu L, et al. Open talus fractures: early infection and its epidemiological characteristics. J Foot Ankle Surg 2019;58(1):103-108. DOI: 10.1053/j.jfas.2018.08.020.

60. Schwartz A, Runge W, Hsu A, et al. Fractures of the talus: current concepts. Foot Ankle Orthop 2020;5(1):1-10. DOI: $10.1177 / 2473011419900766$.

61. Spierings KE, Min M, Nooijen LE, et al. Managing the open calcaneal fracture: a systematic review. Foot Ankle Surg 2019;25(6):707-713. DOI: 10.1016/j.fas.2018.10.005.

62. Güven M, Ozkan NK, Cakar M, et al. Successful treatment of bilateral open calcaneal fractures with concomitant lower extremity injuries: a case report. Cases J 2014;1(1):1-5. 